\title{
PENGEMBANGAN MODEL PENGELOLAAN PEMBELAJARAN PENDIDIKAN AGAMA ISLAM (PAI) DI SEKOLAH DASAR SE- KECAMATAN LUBUK SIKARAH KOTA SOLOK
}

\author{
Rifdahayati \\ Pengawas Guru Pendidikan Agama Islam (PAI) \\ Kecamatan Lubuk Sika rah Kota Solok \\ J. Cindur Mato, Gang Rantau No 12. Kelurahan PPA. \\ Kecamatan Tanjung Harapan Kota Solok
}

1300

\begin{abstract}
This research due to the learning Islamic Education (PAI) at grade IV Primary School Lubuk Sikarah Solok was focused on cognitive aspects, the learning management less managed by the teacher so that the learning management tends to be static. This research was aimed at producing a model of learning management for PAI at grade IV Primary School Lubuk Sikarah Solok. This research was classified into Research and Development by using Thiagarajan model (define, design, develop and dissemination). Data were collected through validation techniques, observation and interviews. The findings showed that the model was valid with $80.625 \%$; and practical with $79.025 \%$.
\end{abstract}

Keywords: Model, Management, Learning, Islamic Education

\section{PENDAHULUAN}

Sekolah mempunyai peran sebagai lembaga pendidikan yang mengembangkan potensi siswa yang manusiawi, agar mampu menjalani tugas dalam kehidupan, baik secara individual maupun sosial. Sekolah suatu organisasi kerja yang terdiri dari beberapa kelas. Setiap kelas mempunyai perjenjangan sendiri. Menurut Nawawi (1989: 117) sekolah dan kelas diselenggarakan untuk memenuhi kebutuhan masyarakat dalam mendidik siswa, yang tidak harus didewasakan dari aspek intelektualnya saja, akan tetapi dalam aspek kepribadiannya.

Salah satu usaha pemerintah untuk menciptakan peserta didik yang berilmu pengetahuan dan berkepribadian yang mulia adalah dengan mengintensifkan pembelajaran Pendidikan Agama Islam di sekolah-sekolah mulai dari jenjang Taman Kanak-kanak (TK), Sekolah Dasar (SD), Sekolah Menengah Pertama (SMP), Sekolah Menengah Atas (SMA), dan Perguruan Tinggi (PT). Pendidikan Agama Islam (PAI) adalah upaya sadar dan terencana dalam menyiapkan peserta didik untuk mengenal, 
memahami, menghayati, hingga mengimani ajaran agama Islam diikuti dengan tuntunan untuk menghormati penganut agama lain dalam hubungannya dengan kerukunan antar umat beragama hingga terwujud kesatuan dan persatuan bangsa (Madjid dan Dian, 2005: 130).

Berbicara tentang konsep pengelolaan dalam pembelajaran, pengelolaan merupakan tindakan-tindakan yang menuju kepada kegiatan-kegiatan yang menciptakan dan mempertahankan kondisi yang optimal bagi terjadinya proses belajar (Rohani dan Abu, 1991: 117). Pengelolaan pendidikan dapat juga diartikan sebagai serangkaian kegiatan merencanakan, mengorganisasikan, memotivasi, mengendalikan, dan mengembangkan segala upaya di dalam mengatur dan mendayagunakan sumber manusia, sarana dan prasarana untuk mencapai tujuan pendidikan.

Menurut Manullang (2005: 5) manajemen atau pengelolaan merupakan sebuah seni dan ilmu perencanaan, pengorganisasian, penyusunan, pengarahan, dan pengawasan sumber daya untuk mencapai tujuan yang sudah di tetapkan. Sedangkan Ramyulis (2011: 259) menyatakan bahwa pengertian yang sama dengan hakikat manajemen adalah al tadbir (pengaturan). Kata ini merupakan derivasi dari kata dabbara (mengatur) yang terdapat dalam Al Qur'an. Seperti firman Allah SWT dalam Q.S Al Sajadah ayat 5 "Dia mengatur urusan dari langit ke bumi, kemudian (urusan) itu naik kepadanya dalam satu hari yang kadarnya adalah seribu tahun menurut perhitunganmu".

Dalam rangka mencapai tujuan pendidikan di lembaga pendidikan, maka prinsip-prinsip dan teori manajemen sebagai teknik pengelolaan organisasi penting untuk diterapkan. Menurut Syafaruddin (2005: 122) mengatakan manajemen pendidikan suatu usaha penerapan prinsip-prinsip dan teori manajemen dalam aktivitas pendidikan pada lembaga lembaga pendidikan untuk mencapai tujuan pendidikan secara efektif dan efisien.

Tujuan pengelolaan pendidikan harus berorentiasi pada peserta didik, yaitu pengembangan kepribadian dan kemampuan dasar peserta didik. Berdasarkan prosesnya, manajemen pendidikan harus dilandasi prinsip-prinsip edukatif, yaitu bahwa proses dalam manajemen pendidikan tidak hanya dilandasi oleh prinsip efektivitas dan efisiensi tetapi juga harus dilandasi oleh prinsip mendidik. Apabila dilihat dari hasilnya, manajemen pendidikan bertujuan untuk menciptakan peserta didik yang berkualitas dan mandiri. Adapun fungsi dari manajemen atau pengelolaan terdiri dari perencanaan (Planning), pengorganisasian (Organizing), penggerakan (Actuating), pengawasan 
(controlling). Fungsi-fungsi manajemen tersebut harus diterapkan secara simultan, integrative dan berkesinambungan.

Setiap mata pelajaran memiliki ciri khas atau karakteristik tertentu yang dapat membedaknnya dengan mata pelajaran lainnya, begitu juga halnya mata pelajaran PAI. Karakteristik mata pelajaran PAI sebagaimana dijelaskan dalam buku pedoman khusus PAI adalah pertama, pendidikan agama Islam (PAI) merupakan mata pelajaran yang dikembangkan dari ajaran-ajaran pokok agama Islam. Kedua, pendidikan agama Islam (PAI) bertujuan membentuk peserta didik agar beriman dan bertakwa kepada Allah SWT, serta memiliki akhlak mulia. Ketiga, PAI mencakup tiga kerangka dasar, yaitu aqidah, syari`ah, dan akhlak.

Pelaksanaan PAI pada dasarnya akan bermuara pada terbentuknya peserta didik yang memiliki akhlak yang mulia (budi pekerti yang luhur). Akhlak mulia ini merupakan misi utama diutusnya Nabi Muhammad SAW. di dunia. Dengan demikian, pendidikan akhlak (budi pekerti) adalah jiwa PAI. Mencapai akhlak yang karimah (mulia) adalah tujuan sebenarnya dari pelaksanaan Pendidikan Agama Islam (Tim Pengembang Ilmu Pendidikan, 2007: 4).

Dalam konteks pembelajaran bahwa model merupakan suatu desain yang menggambarkan suatu proses, rincian dan penciptaan lingkungan belajar yang memungkinkan peserta didik berinteraksi, sehingga terjadi perubahan atau perkembangan pada diri peserta didik (Sukmadinata, 2004: 209). Pada dasarnya dalam pembelajaran tidak ada model yang paling baik, karena setiap model pembelajaran saling memiliki keunggulan masing-masing. Model pembelajaran yang baik dan tepat pada suatu mata pelajaran, belum tentu baik dan cocok diterapkan pada mata pelajaran lainnya. Oleh karena itu, seorang pendidik diharapkan memiliki pengetahuan dan kemampuan dalam memilih dan menerapkan berbagai strategi pembelajaran, agar dalam melaksanakan tugasnya dapat memilih alternatif strategi yang dirasakan sesuai dengan tujuan pembelajaran yang telah dirumuskan yang mengakomodir aspek kognitif, afektif, dan psikomotorik.

Peneliti melihat model pengelolaan pembelajaran yang diterapkan di Sekolah Dasar se-Kecamatan Lubuk Sikarah Kota Solok masih monoton dan kurang terkelola dengan baik. Pengelolaan pembelajaran yang kaku dan cenderung statis mengakibatkan nilai-nilai yang terkandung dalam pembelajaran pendidikan agama Islam (PAI) kurang tersampaikan dengan baik. Akibatnya, banyak peserta didik dan lulusan 
sekolah dasar tersebut yang kurang memiliki etika, kurang bisa baca tulis Al Qur'an, bahkan banyak dari siswa yang tidak hafal bacaan solat. Agar tujuan pendidikan tercapai dengan baik, maka model pengelolaan pembelajaran harus dikembangkan menjadi model pengelolaan pembelajaran yang mengakomodir kompetensi kognitif, afektif dan psikomotorik siswa.

\section{METODE PENELITIAN}

Penelitian yang dilakukan peneliti di sini adalah penelitian pengembangan atau disebut juga Research and Development. Research and Development adalah metode penelitian yang digunakan untuk menghasilkan produk tertentu dan menguji keefektifan produk tersebut (Sugiyono, 2007: 407). Untuk menilai produk yang dirancang maka dalam penelitian ini dilakukan uji validasi dan praktikalitas terhadap pengelolaan pembelajaran pendidikan agama Islam di sekolah dasar se-Kecamatan Lubuk Sikarah Kota Solok.

Rancangan penelitian yang digunakan dalam penelitian ini adalah model pengembangan 4-D oleh Thiagarajan, Semmel dan Semmel. Model pengembangan 4-D terdiri atas 4 tahap pengembangan (Trianto, 2009: 189) yaitu tahap pendefenisian (define), tahap perancangan (design), tahap pengembangan (develop), tahap penyebarluasan (disseminate). Akan tetapi, di karenakan biaya dan waktu yang dibutuhkan cukup besar, tanpa mengurangi arti dari penelitian, penelitian ini hanya dibatasi pada tahap tiga, yaitu pada tahap pengembangan dan sampai pada tahap praktikalisasi.

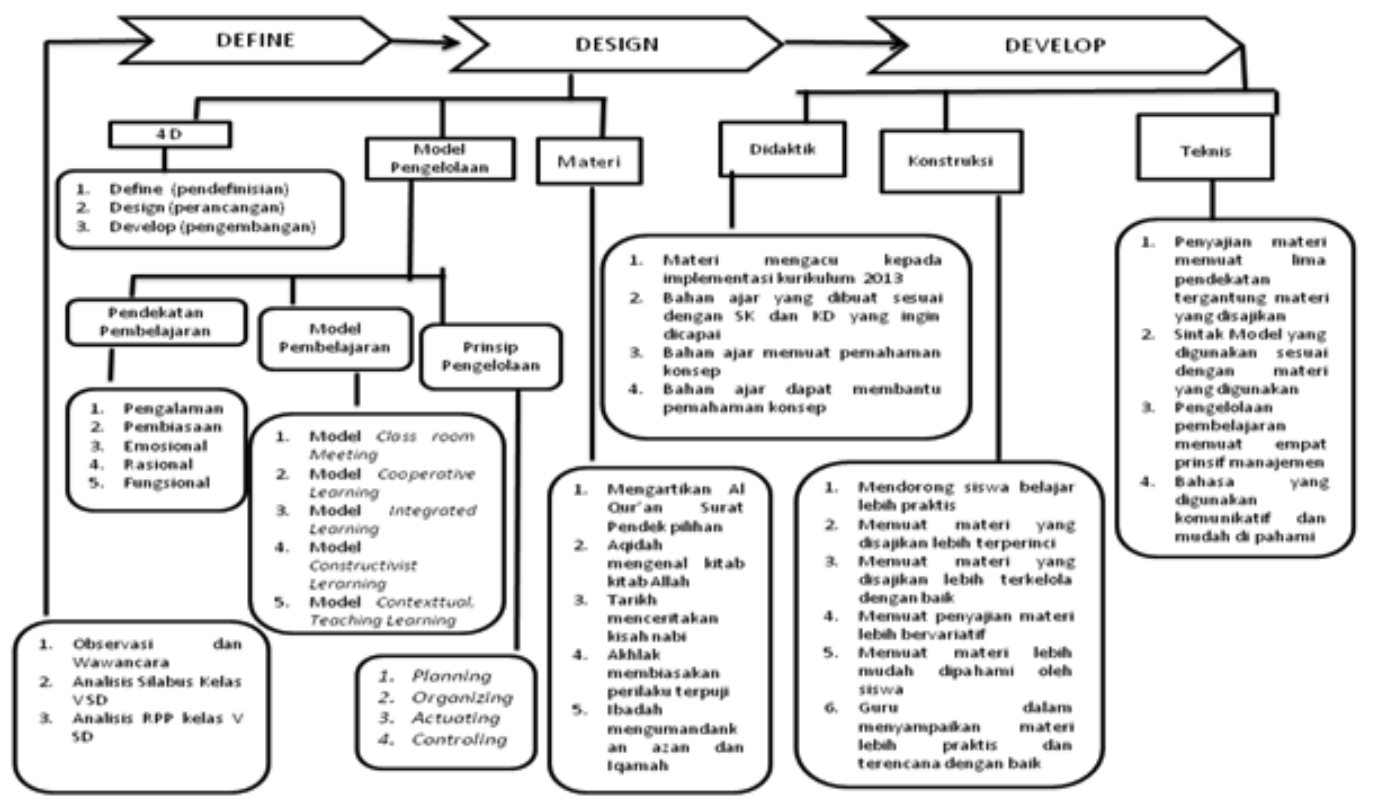

Gambar Konstruksi Model Pengelolaan Pembelajaran PAI di Sekolah Dasar (SD) se Kecamatan Lubuk Sikarah Kota Solok 


\section{HASIL PENGEMBANGAN}

\section{Tahap Define (Pendefinisian)}

Tahap pendefinisian dilakukan dengan melakukan analisis kebutuhan tentang model pengelolaan pembelajaran pendidikan agama Islam (PAI). Kemudian hasil analisis di lapangan sebagai dasar bagi peneliti untuk merancang prototipe model pengelolaan yang lebih praktis untuk diterapkan di Sekolah Dasar se-Kecamatan Lubuk Sikarah Kota Solok. Tahap ini peneliti mulai dengan melakukan wawancara dengan guru mata pelajaran pendidikan agama Islam dan observasi ke sekolah. Selain itu, penulis juga melakukan analisis terhadap silabus dan Rencana Pelaksanaan Pembelajaran (RPP) yang digunakan guru dalam proses pembelajaran.

Berdasarkan wawancara dan observasi yang peneliti lakukan terhadap pengelolaan RPP dan silabus, peneliti menemukan bahwa ditinjau dari aspek pengelolaan yang baik sebagaimana pengelolaan berdasarkan aspek-aspek manajemen masih kurang terlaksana. Akibatnya, pengelolaan proses pembelajaran kurang praktis dalam mencapai tujuan pembelajaran. Seperti yang diungkapkan salah seorang guru agama di lingkungan Sekolah Dasar di Kecamatan Lubuk Sikarah, Darni Witri. Ia mengatakan bahwa "memang harus diakui, selama ini kelemahan sebahagian guru pendidikan agama Islam di lingkungan Sekolah Dasar se-Kecamatan Lubuk Sikarah Kota Solok terletak dalam pengelolaan waktu proses pembelajaran, guru terlalu fokus terhadap satu langkah pembelajaran sehingga kegiatan berikutnya kurang terlaksana.

Berdasarkan analisis yang peneliti lakukan tentang model pengelolaan pembelajaran pendidikan agama Islam (PAI) di Sekolah Dasar se-Kecamatan Lubuk Sikarah Kota Solok, peneliti menemukan bahwa model pengelolaan yang sedang diterapkan perlu untuk direvisi atau dikembangkan.

\section{Tahap Design (Perancangan)}

Tahap design (tahap perancangan) dilakukan setelah peneliti melakukan analisa yang mendalam terhadap model pengelolaan pembelajaran pendidikan agama Islam pada tahap define. Tahap design (tahap perancangan) dilakukan setelah peneliti menemukan bahwasanya model pengelolaan pembelajaran Pendidikan Agama Islam (PAI) perlu diadakan perbaikan. Prototype model pengelolaan pembelajaran pendidikan agama Islam (PAI) yang dirancang, menjadikan guru sebagai acuan dalam proses pembelajaran dan dikembangkan mengacu pada tiga syarat antara lain sebagai berikut.

a. Syarat didaktik, adalah mengacu kepada implementasi kurikulum 2013, 
bahan ajar yang dibuat sesuai dengan Kompetensi Inti (KI) dan Kompetensi Dasar (KD), bahan ajar memuat pemahaman konsep, bahan ajar memuat pemahaman nilai, bahan ajar yang digunakan dapat membantu siswa dalam pemahaman konsep dan nilai.

b. Syarat konstruktif, yaitu mendorong siswa belajar lebih praktis, memuat materi yang disajikan lebih terperinci, memuat materi yang disajikan lebih terkelola dengan baik, memuat penyajian materi lebih bervariasi, materi yang dimuat lebih dipahami siswa, guru dalam menyajikan materi lebih praktis dan terkelola dengan baik

c. Syarat teknis, yaitu penyajian materi memuat empat prinsip manajemen, penyajian materi memuat model pembelajaran untuk setiap materi ajar, penyajian materi berdasarkan sintak model pembelajaran yang digunakan sesuai dengan materi ajar, penyajian materi memuat lima pendekatan tergantung kepada langkah-langkah penyajian, bahasa yang digunakan komunikatif dan mudah dipahami

Penerapan model pengelolaan pembelajaran Pendidikan Agama Islam (PAI) di Sekolah Dasar se-Kecamatan Lubuk Sikarah Kota Solok yang dikembangkan berdasarkan ketiga syarat tersebut dan kriteria di bawah ini.

a. Prinsip prinsip manajemen yang terdiri dari prinsip perencanaan, prinsip pengeorganisasian, prinsip pelaksanaan, prinsip pengawasan.

b. Pendekatan pendekatan pembelajaran, yang terdiri dari; pendekatan pembiasaan, pendekatan pengalaman, pendekatan funsional, pendekatan rasional, pendekatan emosional.

c. Model pembelajaran, yang terdiri dari model constructivist learning, model contextual teaching learning, model clasroom meeting, model constructivist learning, model klarifikasi nilai.

\section{Tahap Develop (Pengembangan)}

a. Tahap Validasi Prototype Pengembangan Model Pengelolaan Pembelajaran Pendidikan Agama Islam (PAI)

Prototype Model pengelolaan pembelajaran pendidikan agama Islam yang sudah dirancang tersebut divalidasi oleh validator antara lain pakar PAI, pakar teknologi, pakar bahasa, dan pakar manajemen.Validator menilai prototype model pengelolaan pembelajaraan pendidikan agama Islam (PAI) untuk diterapkan pada proses pembelajaran di sekolah dasar se Kecamatan Lubuk Sikarah 
Kota Solok. Menurut Riduwan (2005: 81) di katakan valid apabila memiliki persentase dari 61-80\%. Setelah dilakukan validasi terhadap pakar, prototype yang peneliti rancang dinyatakan valid oleh validator sebesar $80,625 \%$.

b. Tahap Praktikalitas Prototype Pengembangan Model Pengelolaan Pembelajaran Pendidikan Agama Islam (PAI)

Uji praktikalitas dilakukan agar prototype yang dirancang tersebut betul-betul bisa diterapkan dan memiliki kelebihan dibandingkan dengan model pengelolaan pembelajaran yang umum diterapkan. Dalam uji praktikalitas yang peneliti lakukan di Sekolah Dasar se-Kecamatan Lubuk Sikarah Kota Solok, peneliti menemukan bahwa prototype model tersebut praktis dan mudah untuk diterapkan sebagai model pengelolaan pembelajaraan pendidikan agama Islam (PAI) di Kota Solok. Dengan nilai persentase $79.025 \%$. Diketahui bahwa dikatakan suatu produk yang dikembangkan tersebut praktis dan mudah untuk diterapkan apabila memperoleh nilai dari 61-80\%.

\section{KETERBATASAN PENELITIAN}

Berdasarkan hasil observasi dan respon siswa yang dilakukan untuk mengamati kendala-kendala yang dihadapi adalah sebagai berikut:

1. Model Pengelolaan Pembelajaran Pendidikan Agama Islam yang dirancang oleh peneliti seharusnya dapat dikembangkan untuk seluruh kelas di Sekolah Dasar (SD) se-kecamatan Lubuk Sikarah Kota Solok namun karena keterbatasan waktu peneliti hanya baru bisa merancang untuk kelas IV Kurikulum 2013

2. Pelaksanaan Model Pengelolaan Pembelajaran Pendidikan Agama Islam yang terkait dengan aspek manajemen dan pendekatan melalui pembiasaan, tidak cukup waktu ketika proses pembelajaran berlangsung saja, namun butuh waktu yang lama dan perlu kerja sama di semua pihak, terutama orang tua sehingga hasil/tujuan yang diharapkan belum bisa dilihat setelah proses pembelajaran berlangsung. Peneliti berharap kepada guru PAI di Kecamatan Lubuk Sikarah Kota Solok agar dalam pengelolaan yang terkait dengan pengawasan perlu mengadakan sosialisasi dengan orang tua siswa atau membuat buku penghubung dengan orang tua siswa, agar tujuan dari pembelajaran PAI sebagaimana yang diamanatkan oleh Rasulullah SAW benar-benar dapat dilaksanakan oleh para siswa. 
3. Berkaitan dengan pelaksanaan uji praktikalitas model pengelolaan pembelajaran pendidikan agama Islam (PAI) di Sekolah Dasar se-Kecamatan Lubuk Sikarah Kota Solok dilakukan oleh peneliti hanya sekali. Akan tetapi, pengawasan akan keterlaksanaan prototype model peneliti lakukan sekali seminggu dalam jangka dua bulan.

\section{KESIMPULAN}

1. Model pengelolaan pembelajaran Pendidikan Agama Islam (PAI) yang dirancang memenuhi prinsip prinsip manajemen yang terdiri dari prinsip perencanaan, prinsip pengorganisasian, prinsip pelaksanaan, dan prinsip pengawasan;

2. Model pengelolaan pembelajaran Pendidikan Agama Islam (PAI) yang dirancang memuat sintak pembelajaran berdasarkan model tertentu dalam setiap materi ajar;

3. Metode dalam pengelolaan pembelajaran Pendidikan Agama Islam (PAI) dalam proses belajar mengajar, sesuai dengan karakter materi ajar;

4. Model pengelolaan pembelajaran Pendidikan Agama Islam (PAI) memuat berbagai pendekatan pembelajaran di setiap langkah atau skenario proses belajar mengajar;
5. Berdasarkan validasi yang dilakukan validator diketahui bahwa prototype yang dirancang valid untuk diujikan dengan persentase $80.625 \%$; dan

6. Berdasarkan hasil angket praktikalisasi terhadap guru pendidikan agama Islam (PAI), diketahui bahwa model tersebut praktis dan membuat guru lebih mudah dalam penyajian materi dengan persentase $79.025 \%$. Begitu juga berdasarkan observasi yang penulis lakukan, model pengelolaan pembelajaran pendidikan agama Islam yang telah dikembangkan tersebut praktis dan membuat guru lebih mudah dalam penyajian materi.

\section{SARAN}

1. Guru diharapkan dalam mengelola pembelajaran agar lebih fokus dalam menyajikan materi di kelas;

2. Guru diharapkan untuk semakin berinovasi dalam mengelola pembelajaran di kelas agar diperoleh hasil yang maksimal;

3. Sekolah hendaknya melakukan pengawasan yang ketat terhadap proses belajar mengajar di kelas, agar proses belajar mengajar berjalan baik dan lancar;

4. Dinas pendidikan Kota Solok diharapkan lebih aktif dalam melakukan evaluasi 
terhadap guru dan sekolah yang kurang melakukan inovasi terhadap proses belajar mengajar di sekolah.

\section{KEPUSTAKAAN ACUAN}

Madjid, Abdul. dan Dian Andiyani. (2004). Pendidikan Agama Islam Berbasiskan Kompetensi (Konsep dan Implementasi Kurikulum 2004). Bandung: Remaja Rosda Karya

Manullang, Marihot. (2006). Dasar Dasar Manajemen. Yogyakarta: UGM Press

Nawawi, Hadari. (1989). Organisasi Sekolah dan Pengelolaan Kelas Sebagai Lembaga Pendidikan. Jakarta: Mas Agung

Ramayulis. (2011). Ilmu Pendidikan Islam. Jakarta: Kalam Mulia

Riduwan. (2005). Belajar Mudah Penelitian untuk Guru, Karyawan dan Peneliti Pemula. Bandung: Alfabeta

Rohani H. Ahmad M dan Abu Ahmadi. (1991). Pengelolaan Pengajaran. Jakarta: Rineka Cipta

Sagala, Syaiful. (2011). Konsep dan Makna Pembelajaran. Bandung: Alfabeta

Saleh, Abdul Rachman. (2007). Madrasah dan Pengembangan Anak Bangsa, Visi, Misi dan Aksi. Jakarta: Rajawali Press
Sukmadinata, Nana Syaodih. (2004). Kurikulum dan Pembelajaran Kompetensi. Bandung: PT Remaja Rosdakarya

Sugiyono. (2007). Metode Penelitian Pendidikan, Bandung: Alfabeta

Syafaruddin. (2005). Manajemen Lembaga Pendidikan Islam. Jakarta: Ciputat Press

Tim Direktorat Pendidikan Madrasah. (2010). Wawasan Pendidikan Karakter dalam Islam, Jakarta: Direktorat Pendidikan Madrasah Kementerian Agama

Tim Pengembang Ilmu Pendidikan FIP-UPI. (2007). Ilmu dan Aplikasi Pendidikan. Bandung: Imtima.

Trianto. (2009). Mendesain Model Pembelajaran Innovatif-Progresif. Jakarta: Kencana

Undang Undang Republik Indonesia No 20 Tahun 2003 tentang Sisdiknas \& UU No 14 Tahun 2005 Tentang Guru dan Dosen.

Usman, Husaini. (2006). Manajemen, Teori, Praktek, dan Riset Pendidikan. Jakarta: Bumi Aksara 